\title{
Intonation as Metaphors in the Song 'Kama Nikifa Kesho' by Diamond Platnumz
}

\section{Joseph Thiong'o \\ David Barasa}

\section{Abstract}

Intonations in songs and oral poetry are not only symbolic in their ability to signify cultural notions informing associated particular oral nuances, but also embody rhetorical practices. This is evidenced in the manner in which intonations shift the literal and semantic meaning of artistic work due to their paralinguistic nature. Although there are a number of scholarly works on literary meanings embodied in songs, the role of intonation as a poetic practice in the criticism of songs has not been exhaustively explored. Thus, this paper examines literary meaning implied in intonations in Diamond Platnumz's song 'Kama Nikifa Kesho'. The paper explains how the artist conveys multi-layered meanings in his application of intonations as a poetic technique. As the article argues, intonation features in the song 'Kama Nikifa Kesho' operate on deferrals procedures where the rising and falling tonal contours at the end of each line presents the dilemma that the persona faces, upon contemplation of his state after his physical death.

Keywords: Intonation, tonal contours, melodic progression, pitch, implycatures

\section{Introduction}

Intonation conveys information in speech which is independent of the words and their sounds. The prominence of intonation is usually manifested as greater duration, greater intensity (the primary physical correlate of loudness), and in the majority of cases a pitch accent (see e.g. Nolan 2005: 7). 'Speakers often 
imply more meaning than what they directly describe in the sentence' (Dennison 2010: 1). Therefore, meaning derived from intonations can be understood in the context of what the speaker implies. As this article shows, intonations in songs function to suggest meanings that are not likely to be discerned in the transcribed version of a song. This is because through intonation an artist is able to convey one's emotions and attitudes regarding the thematic concerns that (s)he articulates. The rising and falling of tonal contours are thus mapping strategies through which the artists express their perspectives regarding the themes that they sing about. On the other hand, the listeners identify with the meaning embodied in tonal units as a result of the shared knowledge and cognitive environment of the artist and the audience. This is in line with cultural meanings associated with manner of intoning, where, 'accentual information is processed separately from segmental information' (Dennison 2010: 114). In addition, accents may have different levels of prominence. One accent may be perceived as more prominent than another due to its variation in height or amplitude, or to location in the intonational phrase (Hirschberg 2004:518). Hirschberg explains further that:

Pitch accents render items intonationally prominent. This prominence can be achieved via different tone targets, as well as differences in $\mathrm{f}_{0}$ height, to convey different messages .... So, items may be accented or deaccented and, if accented, may bear different tones, or different degrees of prominence, with respect to other accents (Hirschberg 2004: 517-518).

Sound travels in frequencies, and $\mathrm{f}_{0}$ in this context can be understood as fundamental frequency, i.e. the movement of sound in curves and the effect it has on meaning based on the perceivable character sound makes in a given context, thus disambiguating implied meaning in an utterance. For instance, a polite request in the utterance 'Shut that door' and a harsh command 'Shut that door!' conveys the implicatures of politeness or command as a result of the difference in sound frequency that is the contour of the voice and the resulting meaning thereof. Fundamental frequency $\left(\mathrm{f}_{0}\right)$ in this regard determine implied meaning based on the acoustic effects and the resultant effect a given sound instantiates based on the space within which it occurs.

The song 'Kama Nikifa Kesho' is a poetic discourse, expressing feelings and imagination through specific rhythms. However, its aesthetic 
aspects may conceal the formality implied in the piece of music. The aesthetic features do not necessarily extinguish the formal aspects of a song. The aesthetic features in this regard conceal the seriousness that inform the intentions and expectations of a given composition. The understatement discernible in concealed formalities thus can be construed as litotes. As further discussed below, an interrogation of the choice of appropriation of a given melodic progression expresses the explicit meaning of the melodic structure. In addition, it informs the choice of the harmonic structures that are differed. There are several ways in which the singer can intone the meaning in a given musical phrase. In this context, the poetic effect of the intonation pattern one opts for can be read as semantic and pragmatic implicatures.

The relationship between pitches echoes the listener's mind and is intended to present the semantic connotation associated with a given manner of expression that convey specific nuances. Such pitch differences can be analysed to reveal underlying contexts that inform the much-suggested meaning as cultural embodiments. This is because meaning emerges from the languages, beliefs, practices, institutions and desires of particular historically located cultures (Malpas, 2006: 55).

Intonation can have three iconic functions (Von Heusinger 1999: 22):

(i) the tendency of pitch to drop at the end of an utterance, and to rise (or at least not to drop) at major breaks where the utterance remains incomplete;

(ii) the use of higher pitch in questions, raises the speaker's interest, and the exchange is incomplete until the addressee answers; and (iii) the use of local pitch peaks (e.g. pitch accents) on words of special importance or newsworthiness in an utterance.

These observations can however be questioned whereby one may ask, whether, as (i) above indicates, all cases where there is a rise or drop in intonation suggest the same outcome. Is it possible to have cases where the degree of rise or fall functions to present different meanings? Does language, context and culture influence poetic meanings implied in intonations? We hereby argue that intonation as paralinguistic features in songs convey dramatic images in the listeners mind. Intonations bear nuances that convey the speaker's attitude where the listener can construe even the opposite of what is stated thus underscoring the irony in a speaker's intonation. Attitude in this context is a 
process of the performing of meaning and not a state of mind. This proposition borrows from current developments in the study of style and transitivity in text, where it has been argued that,

... the grammar of transitivity is more centrally concerned with consciousness rather than with animacy, potency or volitionality (Halliday \& Matthiessen, 2014).

Von Heusinger (1999:16) maintains that intonation is linguistic. In this regard, intonation can be construed as linguistic when purely related to the formal structure but can also be paralinguistic when related to other factors rather than the structural system. When it is distinctive, intonation is linguistic; when nondistinctive, it is largely paralinguistic.

\section{Deconstruction of Intonations in the Song 'Kama Nikifa Kesho'}

The questioning ideas, notions and concepts that inform how something is understood can unveil new knowledge as a result of questioning what is treated as obvious. This can be achieved by interrogating the assumptions, ideologies and perspectives that inform how meaning is created in a given context. Consequently, when what is treated as obvious is questioned, the notions in which understanding was formed starts to collapse as new knowledge presents different or additional perspectives upon which the old notions are understood and can be questioned on the other hand. This is expressed in the song 'Kama Nikifa Kesho’ below.

\section{$\underline{\text { Line }}$}

$\mathrm{Ai}$ -

Oh vipi Ameneke atanililia

Je wasaniwenzangu wataniimbia- $\mathrm{F}+\mathrm{L}+\mathrm{L}_{2}+\mathrm{F}$

Au litafutika jina langu

Na nyimbo zangu watosikia
$-\mathrm{F}+\mathrm{L}+\mathrm{L}_{2}+\mathrm{F}^{2}+\mathrm{F}$

$-\mathrm{F}$

$-\mathrm{L}_{2}+\mathrm{L}+\mathrm{L}_{2}+\mathrm{F}^{2}+\mathrm{F}+\mathrm{L}$

\section{Syllabic Pitch Patterns}

(Flat)

(Rise and Fall)

(Fall and Rise)

(Fall and Rise)

(Fall and Rise) 
Oh vipi Wasafi watanililia Je ndugu rafikiw atahudhuria Au nitakapokufa sina change Hata mamangu atanikimbia Ni swali gumu sana lakini nauliza sababu ipo siku itafika

Nitakapotenganishwa nafsi na roho

Kwenda milele kupumzika

Sijui wengi watalia kwa uchungu

Amand'o watafurahi

Misiku za munikiitwa kwa

Mungu nitapokatishwa na uhai
$-\mathrm{F}+\mathrm{H}+\mathrm{F}+\mathrm{L}+\mathrm{L}_{2+} \mathrm{L}+\mathrm{F}$

$-\mathrm{F}+\mathrm{L}+\mathrm{L}_{2}+\mathrm{F}$

$-\mathrm{F}+\mathrm{L}+\mathrm{L}_{2}+\mathrm{F}^{2}+\mathrm{F}$

$-\mathrm{L}_{2}+\mathrm{L}+\mathrm{L}_{2+} \mathrm{F}^{2}+\mathrm{F}+\mathrm{L}$
(Rising and Falling)

(Falling and Rising)

(Falling and Rising)

(Rise and Fall)

$$
\begin{gathered}
-\mathrm{H}+\mathrm{H}^{2}+\mathrm{H}+\mathrm{H}^{2}+\mathrm{F}+\mathrm{H}+\mathrm{F}^{2}+ \\
\mathrm{L}+\mathrm{L}_{2}
\end{gathered}
$$

- $\mathrm{L}_{2}+\mathrm{F}+\mathrm{L}_{2}+\mathrm{L}+\mathrm{L}_{2}$

- $\mathrm{L}+\mathrm{F}^{2}+\mathrm{F}+\mathrm{L}+\mathrm{L}_{2}$

- $\left(\mathrm{H}+\mathrm{F}+\mathrm{L}+\mathrm{L}_{2}+\mathrm{H}^{2+} \mathrm{H}\right)$

$\left.-\mathrm{L}_{2}\right)^{2}+\mathrm{H}$

(Rise and Fall)

(Falling)

(Rising)

(Falling)

(Falling)

\section{Chorus}

Ni kama nikifa kesho hivi ninani nitazikwa naye

Oh nani atakumbuka nauliza

Nikifa kesho oh nani

atamwambia mama as I cry

Oh mama mwanao me sina

hata motto mmoja

Wakusingiziwa

Hivi nikiondoka

wasikidanganye haya

Wengi l'onao waliniambia

$$
\begin{array}{ll}
-\mathrm{L}+\mathrm{H}+\mathrm{L}+\mathrm{H}^{2} & \text { (Rising) } \\
-\mathrm{L}_{2}+\mathrm{L}+\mathrm{L}_{2} & \text { (Rise and Fall) } \\
-\mathrm{F}+\mathrm{L}+\mathrm{F}+\mathrm{F}^{2}+\mathrm{F}+\mathrm{L}_{2} & \text { (Falling) } \\
-\left(\mathrm{L}_{2}\right)^{2}+\mathrm{H}^{2}+\mathrm{H}+\mathrm{F}+\mathrm{F}^{2}+\mathrm{FL}+\mathrm{L}_{2} \text { (Falling) } \\
-\mathrm{H}+\mathrm{H}^{2}+\mathrm{H}+\mathrm{F}+\mathrm{F}^{2}+\mathrm{H} \quad \text { (Rise, Fall and Rise) } \\
-\left(\mathrm{L}_{2}\right)^{2}+\mathrm{L}+\left(\mathrm{L}_{2}\right)^{2}+\mathrm{L}+\mathrm{F}^{2}+ \\
\mathrm{F}+\mathrm{H} \quad \text { (Falling) }
\end{array}
$$$$
\text { (Rise and Fall) }
$$$$
-\left(\mathrm{L}_{2}\right)^{2}+\mathrm{H}^{2}+\mathrm{H}+\mathrm{F}+\mathrm{F}^{2}+\mathrm{FL}+\mathrm{L}_{2} \text { (Falling) }
$$
ngoja ngoja etisubiria

$-\left(\mathrm{L}_{2}\right)^{2}+\mathrm{L}+\left(\mathrm{L}_{2}\right)^{2}+\mathrm{L}+\mathrm{F}^{2}+$ $\mathrm{F}+\mathrm{H}$ (Falling)

Na wengine kabisawakakata atuzae

Oh Wakiniambia eti muda wao haujawadia
$-\mathrm{H}+\mathrm{H}^{2}+\mathrm{H}+\mathrm{H}^{2}+\mathrm{F} \quad$ (Rise, Fall; Rise, Fall)

- $\mathrm{L} 2+\mathrm{H}^{2}+\mathrm{H}+\mathrm{L}^{2}+\mathrm{H}^{2}+\mathrm{H}$ (Rise, Partial Fall, Rise, Partial Fall) 
Intonation as Metaphors in the Song 'Kama Nikifa Kesho'
Wataharibu ujana
$-\mathrm{L}+\mathrm{F}+\mathrm{F} 2+\mathrm{F}+\mathrm{L}$
(Rise, Fall)
Wengine pia
$-\mathrm{L} 2+\mathrm{H} 2+\mathrm{H}$
(Rise, Partial Fall)
Baada ya shida wao
wakanikimbia waliniumiza
sana
- $\mathrm{L} 2+\mathrm{H}^{2}+\mathrm{H}+\mathrm{L}^{2}+\mathrm{H}^{2}+\mathrm{H}$ (Rise, Partial Fall, Rise, Partial Fall)

\section{Diamond Lyrics}

$\underline{\text { Kama Nikifa Kesho }}$

Ai, Oh vipi Ameneke atanililia

Je wasani wenzangu wataniimbia

Au litafutika jina langu

Na nyimbo zangu watosikia

Oh vipi Wasafi watanililia

Je ndugu rafiki watahudhuria

Au nitakapo kufa sina change

Hata mamangu atanikimbia

Ni swali ngumu sana

Lakini nauliza sababu ipo siku itafika

Nitapotenganishwa nafsi na roho

Kwenda milele kupumzika

Sijui wengi watalia kwa uchungu

Ama nd'o watafurahi

Mi siku zamu nikiitwa kwa Mungu

Nitapokatishwa na uhai

\section{If I Die Tomorrow}

- Will Ameneke mourn my death

- Will my fellow artistes sing for me?

- Or my name will fade

- And my songs will be forgotten

- Oh will Wasafi cry for me

- Will friends attend the funeral

- Or when I die there will be no change

- Even my mother will forsake me

- It's a very difficult question to

- But I am asking because the day is coming

- When the spirit and the body will be separated

- To rest in eternal peace

- I don't know if many will cry because of pain

- Or that is the time they'll celebrate

- My time to be called in Heaven

- When I'll be separated from life

- If I die tomorrow

- Whom will I be buried with

- Oh who will remember

Oh nani atakumbuka nauliza

Nikifa kesho oh nani atamwambia mama asi
- Who will tell mama not to cry 
Oh mama mwanao me sina hata motto mmoja

Wakusingiziwa hivi nikiondoka

wasidanganye hao

- Mom I don't have a single child

Wengi l'onao waliniambia ngoja ngoja eti subiria

Na wengine kabisa wakakataa tuzae

Oh Wakiniambia

Eti muda wao haujawadia

Wataharibu ujana

Wengine pia

Baada yashi dawao wakanikimbia

Waliniumiza sana....

- So let no one cheat you

- Many told me to wait

- And many more refused to give birth

- Oh telling me

- that their time hasn't come

- They'll spoil their youth

- Others in addition

- because of poverty they left me

- I got very hurt

\section{Chorus}

In the analysis above, we apply the following degree of rise or fall to assess the literary effect of intonation.

\section{Difference in Pitch in Syllables that form a tone unit}

\section{Type of Intonation}

Flat

Raising

Falling

Flat and Rising

Flat and Falling

Falling and Raising

Flat and Half Rising

High and Rising
Semantic implicatures in the song 'Nikifa Kesho'

- Impartial

- Retrospective

- Introspective

- Calls for Attention (Declarant)

- Antecedent

- Conclusive

- Sentimental

- Appeal to Third Party (Intensity Varies with Degree)

The artist ends the last line of the first stanza of the song with a falling intonation though this does not invite a sense of finality in the event of the 
unfolding message. All the lines of the song in this regard are expected to create a build-up of anxiety, at thematic level and communicate psychological anxiety that could have informed the composition. The constant sigh that marks the artistic manner of rendition can be taken to signify the agony of bearing one's own death in the very moment of dying.

The singer however, unveils his wish upon his death to continue to live on the lips of his fellow musicians and in the songs, he will have left behind. The tonal structures in this case indicates the desires and wishes of the persona on the one hand as he comes to terms with the inevitability of his end, while on the other hand this signifies the postponement of one's demise as a wishful thought as evidenced in the carryon line whose idea contests conclusion at the end of the lines. Symbolically, this can be deduced to reflect a manifestation of a state of denial of the persona's eventual death.

The intonational structures in this case, thus, reveal the uncertainties that mark reflection of one's death. The dread of psychological torture on the speaker is revealed in the stressed syllables that carry the rhyme.

ia
ia
gu
kia
lia
ria
ngu
mbia
ika
ho
ka
hi
hai

The ultimate end as the drop from the front high vowel /i/ to front flat vowel /a/ suggests that despite the denial the speaker finally accepts his demise.

\section{Presuppositions Informing Intonation}

The fear of death can be discerned in this case to inform the intonational 
structure in the song, where intonational contours as information structures raise the major concern of the persona who mourns his own death in advance.

The observation that:

'I don't know if many will cry because of pain'

reveals internal unresolved conflict within the speaker not only at lexical level but also at tonal level.

The speaker in this line pre-empts his wish to be mourned by his friends and skepticism for the same.

It can thus be argued that the dilemma that defines the speaker's thoughts as he contemplates his death contributes to the intonational structure, which is meant not only to address the theme of death but also to float in the mind unawares situation of when the speaker will pass on. This is expressed by the artist as follows.

Ai, Oh vipi Ameneke atanililia

Ai, oh, how Ameneke will cry for me

Pre-head Head Tonic Tail

\section{Culture Informing Intonation Features and Intonation Patters}

\subsection{Cultural Structures Informing Intonation Features}

The observation that the speaker would desire to be mourned when he dies resonates with popular cultural beliefs in Africa where death is conceived as a negative occurrence. The falling intonations in this case operationalise the dirge melodic structure. The song can thus be said to be a dirge where intonations functions to appeal to emotions. The singer in this context appears to loathe the very notion of death and assumes that potential listeners would tend to hold similar perceptions about death. The untimeliness of one's death 
thus informs the weeping intonational features as the speaker seeks solace in the very song as an act of self-immortalization.

The song in this case thus functions as a discourse for selfpreservation. The intonational structures lure similar notions in the listeners as they reflect on their own end. This appeal to emotions at intonational level transcends the implied meaning and beyond the lexical level to warrant the same theme that lingers in most of Shakespeare's sonnets such as sonnet 5, 6, $7,8,11,12$ and 116 , to mention a few. Here time is discerned as a metaphor that ties up every segment at the ultimate end, thus marking the ephemeral nature of life despite being what one may hold dearest to oneself.

Unfortunately, linguistic meaning is taken for granted. This is on the understanding that rarely do language users, in daily communication trace back the historical background that informs creation and sustenance of the canon that governs the meaning they associate with texts may they be audio or written. What is taken for granted cannot always be assumed to be optimally correct.

Further below, we analyse meaning discernible in intonations on the understanding that 'distribution of syllables that form a tone-unit adds a certain emotional flavor' (Indangasi' 1988: 53). This emotional flavour results from the variety of a combination of different pitches, intensity and syllable duration which adds life to the tone-unit as a result of sound dynamics that define audio embellishments, which not only convey lexical meaning but in addition, convey symbolic meanings.

This can be scored in musical notations. The literary meaning results from the shared knowledge which listeners employ as they infer meaning in the song. The additional meanings which listeners associate with the syllabic structure of a tone-unit at acoustic level can be referred to as anamnesis. This is the root basis of poetic flavour in tone-units. This section thus has explored poetic, and dramatic meanings that result from the intonations as a result of the artistic employment of intonational structures as communicative units meant to present meaning by suggesting possible implicatures tone-unit.

\subsection{Intonation Patterns}

Intonation patterns in songs, performed poetry, and in drama function to convey implied meanings. This article observes that semantic impression deduced from intonation in songs can be classified into several categories 
which results from the effect the intonation bears on the ensuing meaning. These include: that the intonation patterns above in the song 'Kama Nikifa Kesho' influence the communication by prompting the meaning listeners are likely to discern from the song as a result of manner of expression. The intonational features were summarized as follows.

The intonations in the first line appropriate encyclopaedic knowledge of how people mourn, weep, and express grief. This captures the ostensive behaviour of listeners' attention as an emotional peg, which in the context of the emotions it stirs, prepares the listener psychologically for an emotive song. The very first intonation in this case functions to rise suspense as a poetic rendition technique.

The rising and falling intonation in the second line is rhetorical. This is because it attracts the listeners to the question lingering in the speaker's mind as to how Ameneke will cry on receiving the news of the speaker's death. The intonations frame the question to trigger in the listener a reflective context that in addition warrants a mood of introspection, where the contextual information draws the listener to empathise with the speaker. The message qualifies the song as a dirge where the speaker uses the song to pre-empt his thoughts. The falling and rising intonations in the first stanza serves to define the conflict in the speaker's mind, as he worries of what his friends, relatives and fellow musicians will do about him when he dies. The contextual effect this has on the listeners' inferential communication maximizes the idea that death is inevitable. This calls upon the listener to agonize with the singer as he wonders how those close to him including the mother will treat him upon his death. The concatenation of tonal units in this case functions to coax the listener to reflect on a dreadful topic since many people fear thinking of the day of their death.

The intonational features in this case push the listener ahead of time to think of death before it actually happens. Thematically, death informs interpretation of the essence of life. The speaker transcends the common fear to contemplate his own death. This can be deduced as an act of confronting death on the one hand and acceptance of what denial cannot change. Arguably, the tone-units that rise can be argued to reflect psychological moments where the speaker accepts the hard reality of death, which is suggested in the falling intonations that are employed to signal finality when that day comes to reality.

The wavering intonational features defined by a mix of rising and falling intonations in varying patterns functions to ostensibly communicate the 
dilemma that define the basis of the entire composition. For this reason, the speaker's main concerns as evidenced in the chorus is the question as to who will console the mother and whom will he be buried with, this to mean, who will have been his wife. This is arguably, a reference to the relatively common practice that married couples are buried side by side, next to each other. While the lexical reality functions to convey some autobiographical truth about the artiste - where he was not married by the time he sang the song - the intonations appropriate contextual information which is shared between the artiste and the listeners of how most young unmarried men constantly fear their untimely death. As a result, the intonations ostensibly convey this psychological state of concern or worry which thus focuses the meaning listeners are likely to decipher from the song towards the intended inferential communication.

Both the young and the old are thus swayed to reflect on the psychological disturbance the persona is going through, where the intonational features echo the constant emotions that characterize his private thoughts. The concern, worry and fear the speaker spells out, thus gain maximum relevance because they are shared among many unmarried people who are in the pursuit of finding a marriage partner. This concern would thus form part of the encyclopaedic knowledge listeners would employ in the process of inferring the speaker's predicament. Intonations in this regard aid in maximization of relevance where the song functions as a site for venting private thoughts and frustrations which torment one as they reflect on their personal legacy both young and the old. However, the mournful intonational features, while examined in the context of syllable length, pitch and duration, pre-empts the speaker's desire to cling on to life. Arguably, he would not have appropriated a melancholic tone-unit if he was at peace with death and dying.

The contextual effect this has on meaning thus reaffirms the presence of constant denial which characterizes how potential listeners would treat the topic in their feat to infer the song's intentionality. Emotions manifested in choice of intonation, locate the song as a discourse of reflection, where the intonational structures function to reflect of human incapacity to control fate. The varying intonational patterns can thus reflect the possibility of conventional implicatures where many tend to harbour similar fears, concerns, and worries, about their own fate, and in addition can reflect conversational implicatures that mark subsumed fears which manifest as internal dialogue within most people as they think and reflect on their fate. 
Intonations in this context are metaphorical since they serve to reflect on the irony of time, where despite all struggles, worries and wishful thought, at the end, one surrenders one's achievements, dreams and ambitions to the hand of fate. This symbolic implicature can be deduced from the motif of the falling syllable that predominates how the majority of the lines drop towards the end. This falling or dropping can thus be said to symbolize death. Sound stimuli at intonational level in this context function at cognitive level to vivify maximization of relevance that both the speaker and the listener share as knowledge and which both can assume in responding to ideas and thoughts about one's death.

\section{Conclusion}

We cannot talk of rising or falling intonation without explaining the rise or fall with reference to the poetic meaning this has on a phrase in a song. This is because singers appropriate a pitch contour of a given musical scale and the listener detects the rise with respect to the tonic of the respective scale. Intonations in songs may thus, as this section shows, contain meaning that result from the quality of the notes that are used to form a given phrase. Poetic effects in this regard depend on the quality of the root note of a given intonation, the respective progression and the quality of the last pitch in an intonational phrase. Intonational nuances in this regard act as implicatures in relation to the meaning the singer and the listeners associate with voice qualities such as major, minor, diminished or augmented melodic effects.

It is not enough still to make graphical representations using a line to show how the voice rises or drops. In addition to making the graphical representation one needs to clearly show how the manner of voice propagation along a given melodic contour and not a different melodic structure of the same musical scale, function as ostensive communication. It is therefore possible to discern implied meaning in the manner an artiste raises or drops voice when expressing meaning in a given line. Perhaps, the verbal manner in which one uses the voice to suggest what one implies is an aspect of what makes the song poetic at intonational level. Intonations can thus be explored to unveil poetic meaning implied in the voice of the artiste.

The voice behind 'Kama Nikifa Kesho' as this article observed, sings from the key that will best bring out the mood, tone, and attitude, that defines the major theme in a given stanza. The manifestation of poetic meaning in the 
voice however, depends on the listener's acculturation process for one to be able to read experience not only in the voice and melodic contour but also in the harmonic structures of a given melodic contour.

The harmonics of an intonation thus can be said to define the poesy in a tonal unit. The prominence of the harmonics in the voice comes about as a result of one's appropriation of different phonation and techniques in order to infuse the expected meaning in the voice. The poetic meaning implied in a tonal unit thus does not only rely on the quality of the rise or falling but addition to the respective harmonic effects that results from one's manner of articulation.

\section{References}

Büring, D. 2007. Semantics, Intonation and Information Structure. In Ramchand, G. \& C. Reiss (eds.): The Oxford Handbook of Linguistic Interfaces. Oxford: Oxford University Press.

https://doi.org/10.1093/oxfordhb/9780199247455.013.0015

Dennison, H. 2010. Processing Implied Meaning through Contrastive Prosody. PhD Thesis. University of Hawai'i.

Halliday, M.A.K. \& C. Matthiessen 2014. Halliday's Introduction to Functional Grammar. $4^{\text {th }}$ Edition. London and New York: Routledge. https://doi.org/10.4324/9780203783771

Hirschberg J. 2004. Pragmatics and Intonation. In Horn, L.R.. \& G. Ward (eds.): Handbook of Pragmatics. Oxford: Blackwell.

Indangasi, H. 1998. Stylistics. Nairobi: Nairobi University Press.

Nolan, F. 2005. Intonation. Available at: http://www.archive.org/FNIntonation

Von Heusinger, K. 1999. Intonation and Information Structure. Habilitationsschrift, University of Konstanz.

Malpas, S. 2006. Historicism. In Malpas, S. \& P. Wake (eds.): The Routledge Companion to Critical Theory. London and New York: Routledge.

Joseph Thiong'o PhD Student (Literature) Department of Literature University of Nairobi, Nairobi Kenya 
Joseph Thiong'o \& David Barasa

David Barasa (corresponding author) Department of Language and Literature Education Masinde Muliro University of Science and Technology Kenya

barasa.david1@yahoo.com 